\title{
Analysis of Status of Cultural Cooperation Between China and Nations Alongside the Belt and Road
}

\author{
Yin Zhu \\ School of Foreign Languages \\ North China Electric Power University, NCEPU \\ Beijing, China
}

\begin{abstract}
The paper analyzes the current status of cultural cooperation between China and countries in the Belt and Road region. Based on the previous research and theories, this paper particularly analyzes the cooperation situation in education, technology and tourism, including achievements that have been made, problems have emerged and corresponding suggestions have been proposed. The paper also uses latest statistics, news reports and relevant policies as information sources. Due to numerous opportunities and challenges, the cultural cooperation between China and nations alongside the Belt and Road has promising prospects and bright future.
\end{abstract}

Keywords-The Belt and Road; Cultural cooperation; education; Technology; Tourism

\section{INTRODUCTION}

In the past several years, with implementation and development of the Belt and Road Initiative, more attention is given to this issue. However, the focuses are always limited in the aspects of politics, military and economy. The systematic and comprehensive researches about cultural cooperate between China and countries alongside the Belt and Road are so insufficient that we are in badly need of such academic researches. Nowadays, there are already some research achievements. For example, the book Strategic Studies of the Belt and Road published by commercial press in 2017 analyzes the Belt and Road Initiative in detail. There are also some academic papers talking about the cooperation in a certain area with a certain nation such as Pareto Efficiency Analysis of China-Vietnam Cross-Border Tourism under Belt and Road Strategy. Hailiguli Niyazi and Li Dan wrote the paper The Foundation for Developing the Silk Road Economic Belt---Cultural Cooperation but the analysis is insufficient and no problems are aroused.

The existing researches have some limits and weaknesses in common. Firstly, they all regard the cultural cooperation as a small part attached to the economy; papers focus on cultural cooperation field can hardly be found. Secondly, they all neglect the utilization of news report which is of great impotence and can provide us lots of useful information. Thirdly, seldom do scholars take official real-time dynamics into consideration. That's why most papers are out-dated and fail to keep pace with the policies. Another factor is that even though the number of academic research in Chinese is very small, the English one is even much smaller.

\section{BACKGROUND AND MEANING}

Vision and proposed actions outlined on jointly building Silk Road Economic Belt and 21st-Century Maritime Silk Road was issued by the National Development and Reform Commission, Ministry of Foreign Affairs, and Ministry of Commerce of the People's Republic of China on March 28, 2015. In the proposal, one of the Cooperation Priorities is given to "People-to-people bond", which means promoting extensive cultural and academic exchanges, personnel exchanges, media cooperation, tourism cooperation, science and technology cooperation and so on, "to win public support for deepening bilateral and multilateral cooperation." [1] Although the Belt and Road Initiative mainly covers economic fields, the realization of cooperation in economy still highly depends on cultural cooperation as it is the most important foundation for the mutual facilitation in various areas and for the radiation effect. Only when being open minded and being open to different civilizations, can a nation learn from others and develop its talents and boost its cultural soft power.

What's more, it has been a long time since China and the countries involved cooperated in culture, which can even dates back to ancient times. When spread Chinese culture and expand effects of national soft power, China has always attached great importance to countries alongside the Belt and Road for the reason of geographical relationship and cultural similarity. Thus, great foundation of cultural cooperation lies in these countries. Since the establishment of People's Republic of China (PRC), further and deeper development of national relations have been maintained and many of these countries are friendly neighbors and strategic partners of China.

In addition, "when cooperate with China, countries alongside the Belt and Road most worries that the cooperation would form the resource-export dependence on China and commodities with attractions in price and quality may cause impact on their processing industry." [2]That is why countries alongside the Belt and Road pay more attention to and are more likely to take cooperation in non-resource sectors. And enhancing communication in culture is also a goal which countries in the Belt and Road region want to achieve apart from economic development. As a result, cooperation in culture is worthy of attention. 


\section{GENERAL STATUS}

Generally speaking, in recent years, cultural cooperation between China and nations alongside the Belt and Road has reached new historical height with high frequency as well as high quality.

In a personal way, more and more people become familiar with the Belt and Road Initiative and take part in nongovernmental cultural exchanges in different ways of academic exchanges, travelling, volunteer services, etc.

In the perspective of government, the multi-field, multilevel and multi-channel cooperation is becoming more systematic and normalized. For one thing, a lot of new policies are released. For example, the service passport requires no visa between China and Russia as well as China and Mongolia; China sign consular treaties with Philippine, Pakistan and other countries; China signs cultural cooperation agreements with Uzbekistan, Kazakhstan, Kyrgyzstan and other countries. For another, various kinds of activities are launched by government, ranging from international seminars and forums to exhibitions and sports meetings. Such status shows that the official platform for cultural cooperation is increasing and maturing, which provides effective and reliable guarantee for the expansion of the cooperation.

There is nothing ambitious that outstanding achievements have been made by China and all nations concerned. Although some problems need to be solved and some aspects need to be improved, the cultural cooperation between China and nations alongside the Belt and Road still has promising prospects and bright future.

\section{EDUCATION}

\section{A. Status}

Ministry of Education of People' s Republic of China issued the notice of "to Promote the Joint Development of the Belt and Road Education" on July 15, 2016. The notice says that "example setting and active action in educational field and all sectors of society are required when China initiates to build an educational community in countries alongside the Belt and Road." [3] In recent years, the number of overseas students in China keeps on growing, thanks to the educational projects initiated by China and countries alongside the Belt and Road. Through the cooperation with China, there are more than ten projects that have already been underway in many countries.

At the first Belt and Road Education Summit in Beijing on May 6, 2016, representatives from Malaysia, Pakistan, Poland and some other countries have expressed their willingness in providing financial support for joint educational projects with
China. "Navid Hassan Khan, education attache of the Pakistan Embassy in China, says he expects more Pakistani students to choose China as a destination to pursue their overseas studies." [4] The fact is that China is not only the ideal partner in the eye of governments, it is also the first choice for most students in countries in the Belt and Road region who want to study abroad. China offers preferential policy of scholarship. "In 2003, China provided 11201 governmental scholarship for the Belt and Road related countries, accounting for 34\% of total governmental scholarship for international students studying in China that year." (In Chinese) [2] According to the Vision and proposed actions, China promised to offer 10000 scholarship opportunities to countries alongside the Belt and Road each year. From this, it can be clearly seen that the government has a deep recognition of great significance of the education field.

Language education plays a key role to promote communication among countries. As the educational organization that offers standard and authoritative modern Chinese language for people all around the world, the significance of Confucius Institute speaks for itself. It not only helps to promote Chinese language education level, spread Chinese culture, but also strengthens the friendship with the countries involved. Nowadays, 95 Confucius Institute and 50 Confucius Classroom have been established in the Belt and Road related countries and they are all in good operations.

Meanwhile, other academic activities are being under way as well. From November 27 to 29, 2017, "the Belt and Road Educational Dialogue: Research, Policy and Innovation" was hosted by China Education Scientific Research Institute in Beijing in order to reinforce the communication and cooperation in education. "During the session, representatives had a deep discussion under six themes such as 'attainment and technology innovation in the 21 st century', 'students' communication and cross-border education', 'higher education and academic activities in the future', 'the fourth industrial revolution and future schools', 'entrepreneurship education and youth employment' and 'early childhood development and education'." [5]

In January 2018, Lanzhou University held the first Belt and Road high-end academic forum with the theme of "initiative, vision and realization". And the establishment of Belt and Road Research Center was also announced at the forum. "The fundamental aim of this research center is to services for the Belt and Road Initiative. The research center focuses on the exploitation and utilization of natural resources in Western China and areas along Silk Road Economic Belt; economic and social development; environmental protection; international exchanges and other problems of hot fields." [6] 


\section{B. Existing problems and Suggestions}

Education is an important part of the Belt and Road Initiative proposed by President Xi Jinping in 2013, which aims at promoting economic and cultural ties between China and its neighboring and partner countries. However, there still exist some problems. First, the two-way communication of academy is out of balance. Compared with the scale and number of foreign students studying in China, the amount of Chinese students who are sent to countries in the Belt and Road region are relatively smaller, which means that the bidirectional communication is not enough. And due to the lack of teaching talents of minority language, the quality of the educational cooperation is limited. Second, the urgent demand of compound talents can hardly be met in a short time. There are too few experts specialized in certain areas and knowing foreign languages especially minority languages at the same time. As a result, it is difficult for the educational cooperation to upgrade and make any concrete breakthrough. Third, there are still barriers in Chinese promotion. Some nations are cautious about Chinese learning and hold wait-and-see attitude.

In the future, more people should be sent by China to study in countries in the Belt and Road region and some special funds should also be set up to cultivate the ability of talents with particular skills to master a foreign language and to encourage them to make a study visit in Belt and Road related countries. We should be more familiar with the culture and policy of other countries and make deeper research and exchange. "We lack the knowledge of cultural development of modern central Asian countries and we still need to go further in the deep analysis of main nations' psychology and characteristics, which would probably become the major barriers in policy making, coordinating and implementing that is related to Silk Road Economic Belt."[7] We should dig deeper the charm of Chinese characters and guide the learners of to appreciate it so that they can have the lasting resonance.

\section{TECHNOLOGY}

\section{A. Status}

Firstly, under the Belt and Road Initiative, many scientific research institutions have taken the strategy of "going out" and cooperation of scientific and technological innovation alongside the Belt and Road has gained fruitful achievements. "Nowadays, Chinese Academy of Sciences has established nine science and education institutes overseas and five center of excellence, becoming the open base of technological cooperation with complementary advantages and win-win results." (In Chinese) [8] Every year, there are more than 10000 people involved in the cooperation of scientific and technological communication between Chinese Academy of Sciences and countries in the Belt and Road region.

What's more, "The construction of Belt and Road joint laboratory is under way step by step in areas of agriculture, energy, transportation, information communication, resources and other key areas, fully motivating all kinds of interested parties, integrating the functions of joint research, exchange between scientific talents and their cultivation, shift of advanced and applicable technology and so on to build a long- term and stable cooperation platform of scientific and technological innovation." [9]

Secondly, the cooperation extends to many fields. The range extension and scope expansion can be seen from the number of cooperation partners and the content of cooperation. Besides the traditional partners of developed countries, newly developing Asian-Pacific nations such as Singapore, India also have cooperative relationship in science and technology with china. The technological cooperation with five countries in central Asia mainly covers the following fields: petroleum and gas, new energy resources, chemical engineering, agriculture, nonferrous metal extraction and so on. The technological cooperation with India, Bangladesh, Burma and ASEAN countries mainly focus on biological medicine, energy, water resources development and utilization. The all-round, wideranging and multi-level technological exchange and cooperation with countries in the Belt and Road region have been preliminarily formed. In addition, based on the demand of some countries alongside the Belt and Road, China has given them the assistance of industrial park planning. High-tech zone and Science Park facilitate the deep integration of technology and industry in different countries.

Thirdly, the gradual establishment of platforms lays the foundation of international technological cooperation. Ministry of Science and Technology has launched a series of major projects collaborated with relevant countries and many joint laboratories, research centers and observation stations have been built. "National 305 project office built 'ChinaKazakhstan Science and Technology Cooperation Workstation' with Kazakhstan Institute of Geographical Science in 2010; built 'China-Kyrgyzstan Science and Technology Cooperation Center' with Kyrgyzstan Institute of Geographical Science in 2011; built 'China-Uzbekistan Science and Technology Cooperation Center' with Uzbekistan Institute of Geology and Geophysics in 2013.’[2]

\section{B. Existing problems and Suggestions}

For one thing, the cooperation is restricted to some lower level fields like science and technology for agriculture and people's livelihood. China's neighbor countries in central Asia and south Asia have a relatively low level of technology and industrial system development. Much basic scientific equipment is left by former Soviet Union. As a result, even though there is huge demand of technology in these countries, the ability to cooperate is limited. For another, the investment is not enough. Neither the financial support for technological development nor the policy support is far from enough. For example, there used to be 106 international cooperative projects in Xinjiang province with only 43.75 billion funds. And the transportation of scientific equipment expert personnel require complicated procedures, which pose more barriers for the cooperative.

To handle these problems, national governments should first make medium-term and long-term outline of technological cooperation and plan all departments as a whole. Establish the mechanism of financial support and risk assessment. Meanwhile, China should seize the opportunity to increase the investment in key scientific and technological cooperation and 
set up special funds. Combined with actual developing demand every nation involved should set a clear goal, pinpoint the research direction and put forward cooperation areas where they will focus on and put effort into. The advantages that a country has had and the national conditions should be taken into consideration before any decision is made. A regular multilateral seminar should also be formed to exchange the information and latest achievements so that countries have access to learn from each other regularly.

\section{TOURISM}

\section{A. Status}

There are abundant natural tourism resources in regions alongside the Belt and Road, ranging from natural scenery to humanism resources. For instance, Mount Tianshan, the Altai Mountains, Balkhash Lake, Baikal Lake; Dunhuang, Samarkand and some other ancient cities; the Buddhism monuments of Tower of the city in Burma, Taj Mahal that represents Indian civilization and other famous historic sites. As to the world heritages, China has 50, India has 35 and Bangladesh has 3. What' s more, highly enriched in tourism resources such as alpine and gorge regions, snow covered plateau, endless coastlines, countless islands, Belt and Road regions can meet almost all the demands of tourists and leave them an unforgettable experience.

Belt and Road countries have great tourism potential. Travelling is becoming more and more popular as a choice for people to spend their holidays. There is an obvious increase in the number of Chinese tourists travelling to Belt and Road countries in recent years. And taking the total number of involved population of about 4.4 billion into consideration, the tourism consumption market has an immense potential. "In 2014, the number of two-way tourism exchange between China and Belt and Road countries has reached over 250 million. In the future five years, there will be 150 million Chinese visitors coming to Belt and Road countries, spending more than 200 billion dollars." [2]

The complicated procedures for travelling abroad are being simplified, making the Belt and Road countries more accessible to Chinese consumers and more attractive particularly to the young people. On 29th January, 2018, the online visa center came online, which involves elven Belt and Road countries: Burma, Sri Lanka, India, Azerbaijan, Armenia, Cambodia, Georgia, Kyrgyzstan, Tajikistan, Turkey and Vietnam. "Because all these eleven countries have e-visa and the online visa center allows information to be submitted online during the whole process in those countries and regions that imp e-visa. Thus from now on, consumers can work out the visa to these countries through their mobile phones without going out." (In Chinese)[10] The transportation infrastructure is gradually improved and the transportation network is formed step by step. The major kind of transportation in Belt and Road regions is still air traffic. Nowadays, people can fly to many relevant countries directly and in order to meet the market demands better, more airlines are becoming available.

"According to the statistics published by Xinjiang Bureau of Civil Aviation, in 2017, 17 countries and 24 international (regional) cities have navigations to Urumchi International
Airport, which provides strong support for outboard tourism market." [11].

The formation of international tourism cooperation mechanism is maturing. China and Belt and Road countries have reached an international consensus of tourism development. In 2015, China held the Silk Road Conference of tourism ministers, then bilateral or multilateral tourism cooperation mechanisms are successively set up, such as China -ASEAN, China- Central and Eastern Europe, China-Russia and Mongolia. "China has also set up a community of Maritime Silk Road Tourism Promotion, a community of Silk Road Tourism Promotion, a community of 'the Tea Road' International Tourism Promotion" and so on, to strengthen horizontal cooperation in encouraging travellers to tour in cooperative region, co-constructing the lines, sharing destinations and other aspects with countries, regions provinces and cities along the Belt and Road." [12]

\section{B. Existing problems and Suggestions}

Nowadays, the chief problem is that the tourism pattern is simple and lacks structural diversity. And with insufficient input in tourist industry, the resources are not fully utilized. To realize such goal, relying merely on the government is far from enough. What's more, Belt and Road international tourist environment is in need of improvement and optimization. The case that tourist market order is disturbed happens occasionally. The infrastructures around popular sites can't provide satisfactory accommodation capacity during the tourist season.

Based on the premise that the tourist attractions are well protected, we can further tap the development potential of tourist attractions and constantly improve touring service level. Meanwhile, more special and creative tourist attractions that are based on the cultural heritage values should be constructed. For example, "Dunhuang Academy decided to build 'Moga World: the Theme Park of Silk Roads Grotto Art', involving seven major parts: Glory of Silk Roads, Going Through Extremity, the Buddhism World, the Desert Adventure, Water World, National Artistry and Deep Meditation." (In Chinese) [13] It's time that the pace of tourist industry transformation should be accelerated.

The government should work together with local people to make reasonable development and utilization of tourism resources so that they can benefit both the developer and tourists. "Through the formulation of relevant people-benefit policies, the government can drive borderers to put efforts into development of border tourism for the improvement of their own living level." (In Chinese) [14] Additionally, the government and relevant companies should also work together to propagandize and popularize the Belt and Road tourism brand. It is of great crucial that the establishment of a series of complete supporting facilities be accelerated. National governments should make concerted effort to promote joint supervision of tourist market and harshly crackdown on illegal behavior, ensuring the healthy and sustainable development. 


\section{SUMMARY}

Cultural cooperation between China and nations alongside the Belt and Road has reached new historical height. Outstanding achievements have been made by China and all nations concerned particular in areas of education, technology and tourism but there are still some problems to be solved. Faced with opportunities and challenges, the cultural cooperation between China and nations alongside the Belt and Road has promising prospects and bright future.

In the future, the essence and core of Belt and Road strategy lie in the innovation, through the channel and patent to form a tighter and deeper cooperation. All sectors of society should work together, review the past and sum up the experience of success that has been achieved and draw lessons from the existing problems, and deepen the cultural cooperation between China and nations alongside the Belt and Road.

\section{REFERENCES}

[1] The National Development and Reform Commission, Ministry of Foreign Affairs, and Ministry of Commerce of the People's Republic of China: Vision and proposed actions outlined on jointly building Silk Road Economic Belt and 21st-Century Maritime Silk Road, 2015, http: //language. chinadaily.com.cn/2015-03/30/content_19950951.htm.

[2] Liu Weidong et al. Strategic Studies of the Belt and Road. Beijing: The commercial press, 2017. (In Chinese)

[3] Ministry of Education of People's Republic of China: To Promote the Joint Development of the Belt and Road Education, 2016, http://www.moe.edu.cn/srcsite/A20/s7068/201608/t20160811 274679.html. (In Chinese)

[4] Li Chenxi: China Eyes Broad Prospects for Education Cooperation under "Belt and Road" Initiative, 2016, http://english.cri.cn/12394/2016/05/06/4061s926781.htm.

[5] Chen Mengyao: Belt and Road Education Dialogue: Promote Educational Exchange and Cooperation among Belt and Road Countries, 2017, http: //news.xinhuanet.com/silk road/2017- 11/ 27/c_1 29750538.htm. (In Chinese)

[6] Fang Jin: Lanzhou University Established Belt and Road Research Center, 2018, http://www.cnr.cn/chanjin/jiaoyu/20 180126/t20180126_524113697.shtml. (In Chinese)

[7] Hailiguli Niyazi, Li Dan. The Foundation for Developing the Silk Road Economic Belt----Cultural Cooperation [J]. Journal of Xinjiang University, Vol.40, No.6, 2013, (06): 28-30. (In Chinese)

[8] Tian Tian, Shen Yaxin: The Achievements of the Belt and Road Technological Cooperation Begin to be Seen Gradually, 2017, http://politics.people.com.cn/n1/2017/0510/c1001-292 64783.html.

[9] Wang Jupeng: Cooperation of Technological Innovation Alongside the Belt and Road has Fruitful Achievements, 2017, http //www.ce.cn/xwzx/gnsz/gdxw/201705/11/t20170511_2270 5149.shtml. (In Chinese)

[10] Zhao Tingting: The Online Visa Center of Elven Belt and Road Countries Came Online, 2018,http://epaper.ynet.co m/html/2018 01/30/content_277601.htm?div=-1.

[11] Wang Jie: What does the Belt and Road Bring to Our Life, 2018, http://news.ifeng.com/a/2 0180119/55277738_0.shtml. (In Chinese)

[12] Zhao Shan. Belt and Road Tourism Triples the Heat in Three Years [N]. People's Daily Overseas Edition, 2017-5-15(012). (In Chinese)

[13] Cui Lin: Defending the Holy Place, Dunhuang Explores the Integration of World Heritage and Tourism to Serve the Belt and Road, 2018,http://www.gs.xinhuanet.com/2018-01/29/c_1122 332950.htm.

[14] Jing Jing: Pareto Efficiency Analysis of China-Vietnam Cross-Border Tourism under Belt and Road Strategy [M]. Yunnan: Yunnan University of Finance and Economics, 2016. 